\title{
Brasileiros e ciências sociais no Chile da Unidad Popular
}

\section{Brazilians and social sciences in the Chile of Unidad Popular}

\section{Brasileños y ciencias sociales en el Chile de la Unidad Popular}

\author{
Sergio Salinas ${ }^{1}$
}

\section{Resumen}

En Chile, las ciencias sociales vivieron uno de los momentos de mayor expansión de su historia entre 1967 y el 11 de septiembre de 1973, fecha del golpe militar. Las razones fueron fundamentalmente dos: la "reforma universitaria" y la llegada, producto de su exilio, de destacados intelectuales brasileños, partidarios de la teoría de la dependencia. Este artículo analiza los cambios vividos en las ciencias sociales como la participación de estos intelectuales brasileños en la Unidad Popular.

Palabras-Clave: Chile; Brasil; Ciencias Sociales.

\section{Resumo}

No Chile, as ciências sociais viveram um dos momentos de maior expansão de sua história entre 1967 e 11 de setembro de 1973, data do golpe militar. As razões foram fundamentalmente duas: a "reforma universitária" e a chegada, produto de seu exílio, de destacados intelectuais brasileiros, partidários da teoria de dependência. Este artigo analisa as mudanças ocorridas nas ciências sociais, como a participação desses intelectuais brasileiros na Unidade Popular.

Palavras-Chave: Chile; Brasil; Ciências Sociais.

\begin{abstract}
In Chile, the social sciences experienced one of the greatest moments of expansion in its history between 1967 and September 11th, 1973, date of the military coup. The reasons were basically two: the university reform and arrival, product of their exile, of leading Brazilian intellectuals, supporters of dependency theory. This article analyzes the changes experienced in the social sciences as the participation of these Brazilian intellectuals in the Popular Unity.
\end{abstract}

keywords: Chile; Brazil; Social Sciences.

\footnotetext{
${ }^{1}$ Doctor en Estudios Latinoamericanos, Universidad de Chile. E-mail: ssalinas@uchile.cl.
}

\section{GANPHLAC}

Revista Eletrônica da ANPHLAC, ISSN 1679-1061, №. 18, p. 121-138, jan./jul. 2015.

http://revista.anphlac.org.br/ 
Artigo recebido em: 5 de janeiro de 2015 .

Artigo aprovado para publicação em: 12 de março de 2015

En los últimos años se han producido diversas conmemoraciones del ciclo de golpes militares que sacudió hace más de 40 años a diversos países de América Latina. Lo anterior generó numerosas investigaciones y reflexiones desde puntos de vista no tratados anteriormente. En el caso de Chile, la conmemoración de los 40 años del golpe militar, el 11 de septiembre de 1973, no fue una excepción, produciéndose una verdadera explosión de artículos y libros respecto al tema.

De esta manera, el trágico final del proyecto revolucionario de la Unidad Popular ofreció la ocasión para volver a reflexionar sobre ese período y revisar las historias de sus actores. Entre estos últimos, uno de los temas más interesantes es la llegada a Chile, desde fines de 1960, de varios intelectuales extranjeros que participaron tanto en el proceso de la Unidad Popular como en el partido político que justificaba la lucha armada como estrategia para conquistar el poder: el Movimiento de Izquierda Revolucionaria (MIR). Sin duda, que el grupo de extranjeros de mayor influencia, sobre todo a través de su reflexión académica, en el efervescente proceso social conducido por los sectores populares y la izquierda entre 1960 y 1973, fue el proveniente desde Brasil.

\section{Las ciencias sociales en Chile}

Entre mediados de la década del sesenta y el golpe militar de 1973, "las ciencias sociales experimentaron en Chile un triple fenómeno: de expansión de sus posiciones académicas, de transformación de su estructura conceptual y de cambio de su función en el campo intelectual" (SALINAS, 2013, p. 159). Dos de las razones principales que explican lo anterior se encuentran en el proceso de "Reforma Universitaria" y la llegada de académicos extranjeros.

\section{GANPHLAC}

Revista Eletrônica da ANPHLAC, ISSN 1679-1061, №. 18, p. 121-138, jan./jul. 2015

http://revista.anphlac.org.br/ 
En primer lugar, es necesario señalar que la "Reforma Universitaria", a mediados de la década del 60, creó nuevas oportunidades y condiciones para las ciencias sociales. "Las que se materializaron en el proceso de institucionalización de las ciencias sociales y el aumento del número de matriculados. Además, se experimentó un proceso ampliado de institucionalización: se crearon nuevas unidades académicas, institutos de investigación y carreras profesionales" (SALINAS, 2013, p. 160).

Por ejemplo, se formaron centros interdisciplinarios de ciencias sociales, especialmente en las universidades de Chile y Católica de Chile. Como señala el académico chileno, José Joaquín Brunner (1986, p. 15), lo anterior significó

Que el mercado de posiciones académicas en este sub-campo
disciplinario aumenta explosivamente, multiplicándose los puestos de
investigadores, docentes y administradores superiores en el caso de la
sociología y especialidades conexas". En el caso de la sociología, ésta
experimentó un rápido crecimiento de su base institucional
estableciéndose nuevas escuelas o institutos.

En la Universidad Católica de tanto el Centro de Estudios de la Realidad Nacional (CEREN) y el Centro de Estudios de la Planificación (CEPLAN), representaban, respectivamente, las dos iniciativas más importantes de la reforma en el campo de las ciencias sociales, uno con foco en la sociología y el otro con foco en la economía.

En la Universidad de Chile, se observó un fenómeno similar, aunque menos pronunciado. Se creó el Centro de Estudios Socioeconómicos (CESO), mientras se multiplicaron los programas de economía y ciencias sociales en diversas facultades.

En el campo de las ciencias sociales, principalmente las vinculadas a la sociología, producto de la expansión institucional impulsada por la reforma universitaria, se produjo: el establecimiento de mercado de posiciones académicas más amplio y complejo; el surgimiento de una incipiente jerarquía institucional en el campo de las ciencias sociales, ocupando las posiciones preeminentes los centros de investigación CEREN y CESO; la aparición de una naciente estructura de comunicación académica en el subcampo, en particular mediante la publicación de revistas especializadas como los Cuadernos de la Realidad Nacional, del CEREN;

\section{GANPHLAC}

Revista Eletrônica da ANPHLAC, ISSN 1679-1061, Nº 18, p. 121-138, jan./jul. 2015.

http://revista.anphlac.org.br/ 
Sociedad y Desarrollo, del CESO; y Eure, revista del Centro Interdisciplinario de Desarrollo Urbano (CIDU) (BRUNNER, 1986, p. 15).

Las ciencias sociales cambiaron en Chile de orientación a partir de 1967, pero sobre todo después de 1970, año del triunfo de la Unidad Popular y de la formación del gobierno de la coalición de izquierda. Brunner (1986, p. 15) afirma que:

\footnotetext{
En parte, este fenómeno representa el efecto de una segunda recepción en la sociología chilena, esta vez bajo el impacto de la crítica a la teoría empírica de las ciencias sociales en el contexto de un ascenso de las ideologías de izquierda.
}

En esta situación, se difunde en Chile -como afirma Manuel Antonio Garretón (2005, p. 3) - el modelo del marxismo-ciencia que impulsará, en el campo de las ciencias sociales universitarias, una rápida sustitución del programa de investigación articulado en torno a la teoría de la modernización por el programa de investigación articulado en torno a la teoría de la dependencia.

Por otra parte, hacia 1967 comienza una marcada radicalización política en el país que se traduce luego en franca polarización desde 1970. Tales fenómenos penetraron también en las universidades. Por un lado, a nivel institucional, se transformaron sus estructuras de gobierno en un campo de lucha por el poder, lo que en algunos casos se resolvió por la vía de crear instituciones paralelas, especialmente en el ámbito de las Ciencias Sociales. Por otro, hubo una ideologización temática y de los contenidos de las ciencias sociales, con énfasis apologético o denunciativo de la realidad; sumado a una combinación del uso del marxismo estructuralista althuseriano o poulantziano en el plano teórico, con el leninismo en el plano político, que criticaban la visión estructural funcionalista predominante hasta entonces, por considerarlas vinculadas a las visiones norteamericanas de la guerra fría. Esta visión planteaba que el propósito de la sociedad es el mantenimiento del orden y la estabilidad social, y que la función de las partes de una sociedad y el modo en que estas están organizadas, la estructura social, serviría para mantener ese orden y esa estabilidad. Los principales autores de esta corriente eran Talcott Parsons, Robert Merton, Gabriel Almond y Bingham Powell.

\section{CANPHLAC}

Revista Eletrônica da ANPHLAC, ISSN 1679-1061, N. 18, p. 121-138, jan./jul. 2015.

http://revista.anphlac.org.br/ 
En tercer lugar, el movimiento estudiantil y los alumnos de ciencias sociales mayoritariamente de izquierdas- tendieron a abandonar la universidad y las disciplinas para involucrarse en los procesos de lucha social y estrategias políticas que se jugaban más allá de las aulas. En el horizonte, estaban presentes las elecciones presidenciales de 1970, donde por primera vez la izquierda planteó un proyecto y un programa de socialismo: conformar una área de propiedad social expropiando las empresas monopólicas para ir abriendo camino al socialismo en el marco del régimen democrático.

Pero volvamos a las ciencias sociales. Este cambio de un programa de investigación a otro, con la llegada del marxismo científico, implicó también una redefinición completa de la propia disciplina. No solo cambió su modelo conceptual predominante, sino que cambiaron además los ideales explicativos de la ciencia y la identidad profesional del científico social. El marxismo científico "proporciona precisamente el paradigma sustitutivo y legitima este cambio de orientación en las ciencias sociales, tornándose dominante dentro del subcampo" (SALINAS, 2013, p. 161-162).

Así, la idea de la neutralidad valorativa de la ciencia que había presidido la profesionalización de la disciplina es ahora abandonada, siendo reemplazada por la noción del compromiso valorativo, que opone ciencia académica (o burguesa) a ciencia comprometida o militante. La vocación del científico y del político tiende a fundirse en la imagen del sociólogo como crítico de la realidad, como intelectual revolucionario o como transformador de la sociedad.

En síntesis, a partir de 1970, el sociólogo se vuelve ideólogo; en el campo académico mediante el recurso a un nuevo paradigma de cientificidad (el marxismo) que le permite romper con la sociología "académica" sin abandonar la pretensión de verdad, y en el campo político-social donde se presenta ahora como un organizador de discursos, con efectos directos en la política y como un portador de proyectos de cambio de la sociedad ${ }^{2}$.

\footnotetext{
${ }^{2}$ Se trata, así, de una profundización, radicalización y crisis interna del modelo fundacional, en que las ciencias sociales, especialmente la sociología, se transforman en una expresión -en el campo
}

\section{CANPHLAC}

Revista Eletrônica da ANPHLAC, ISSN 1679-1061, №. 18, p. 121-138, jan./jul. 2015.

http://revista.anphlac.org.br/ 


\section{El aporte de los brasileños}

Otro tema importante en el contexto que presentan las ciencias sociales, lo constituyó la venida a Chile de importantes intelectuales europeos y brasileños de izquierda. Entre ellos, destacaron los brasileños Theotonio Dos Santos ${ }^{3}$, Ruy Mauro Marini $^{4}$ y Vania Bambirra ${ }^{5}$, los que se vincularían tanto a la Unidad Popular como al naciente Movimiento de Izquierda Revolucionaria (MIR). De la misma manera, esta situación se repetiría con uno de los más importantes autores de la teoría de la dependencia, André Gunder Frank ${ }^{6}$.

Helenice Rodrigues da Silva (2007) recuerda que:

[...] A repressão na Universidade de São Paulo, no início de 1969, provoca uma onda de exílio em direção do Chile. A experiência socialista da Unidade Popular atrai, particularmente, os intelectuais brasileiros ávidos de liberdade e de cultura. Além do interesse pela política, o Chile propicia, a esses professores, condições de emprego em suas instituições de pesquisa e em universidades. A Universidade Católica do Chile, por exemplo, vai abrigar alguns profissionais brasileiros, vítimas da repressão. Durante os três anos de governo de Allende, esse país transforma-se em uma espécie de melting pot onde

académico e intelectual- de los procesos y luchas políticas del instante. No es que no hubiera influencia y luchas ideológicas en el momento de fundación e institucionalización de las ciencias sociales; de hecho, las visiones marxistas aparecen como respuesta a ellas, sino que ahora ellas se entrelazan más directamente con los procesos políticos concretos.

${ }^{3}$ Entre las principales publicaciones realizadas en la época en que vivió en Chile se encuentran: Tendencias del Capitalismo Contemporáneo, Santiago, Chile: Ed. de CESO, 1973; Transición al Socialismo y Experiencia Chilena. Santiago: Ed. PLA, 1973. v. 1.; Problemas del Subdesarrollo Latinoamericano. Ciudad de México: Ed. Nuestro Tiempo, 1973. v. 1; Socialismo o Fascismo: El Dilema Latinoamericano y el Nuevo carácter de la Dependencia. Santiago, Chile: Ed. PLA, 1972; Dependencia y Cambio Social. Santiago, Chile: Ed. do CESO, 1972; Economía Política del Imperialismo. Buenos Aires: Ed. Periferia, 1972. v. 1; La Crisis Norte Americana y América Latina. Santiago, Chile: Ed. PLA, 1971; La Dependencia Económica y Política en América Latina. Ciudad de México: Ed. Siglo XXI, 1971. v. 1; El Concepto de Clases Sociales. Santiago, Chile: Ed. PLA, 1970.

${ }^{4}$ Escribió durante su permanencia en Chile Subdesarrollo y Revolución (1969) y Dialéctica de la dependencia (1973).

5 Entre los principales libros publicados a principios de los setenta se encuentran: El capitalismo dependiente latinoamericano, Santiago de Chile, 1973 y reeditado en Siglo XXI, México, 1974; La revolución cubana: una reinterpretación, Ed. Nuestro Tiempo, México, 1974

${ }^{6}$ Entre sus libros publicados en ese periodo se encuentran: Capitalismo y subdesarrollo en América Latina, 1967; Latinoamérica: subdesarrollo o revolución, 1969; Sociología del desarrollo y subdesarrollo de la sociología: el desarrollo del subdesarrollo, 1969; Lumpenburguesía: Lumpendesarrollo. Dependencia, clase y política en Latinoamérica, 1972.

\section{CANPHLAC}

Revista Eletrônica da ANPHLAC, ISSN 1679-1061, №. 18, p. 121-138, jan./jul. 2015.

http://revista.anphlac.org.br/ 
se misturam intelectuais latino-americanos, intelligentsia francesa, como também militantes de esquerda de diferentes partes do mundo.

Theotonio Dos Santos, que estudió Sociología, Política y Administración Pública en la Universidad Federal de Minas Gerais, recuerda que:

[...] Veníamos del proceso brasileño que vivió un gran auge de lucha de masas, sobre todo entre 1960 y 1964, con ello hubo avances democráticos muy importantes. Bueno, el golpe de Estado de 1964, que era resultado de varios intentos anteriores, estaba claramente dentro de una concepción nueva de golpes de Estado porque seguía la idea de crear un régimen con una fuerte base en las fuerzas armadas. Según la interpretación norteamericana, en ese momento estas fuerzas representaban los sectores más modernizantes dentro de América Latina. Por lo tanto, al darle una base estatal más organizada, más coherente, se podía entonces conducir el proceso de modernización (VIDAL, 2013).

Do Santos afirma que muchos de sus compañeros se equivocaron en el diagnóstico del proceso, porque creían que se trataba de un golpe de la antigua oligarquía ligada a la tierra, cuando de hecho era un golpe del gran capital en su forma más avanzada:

[...] Yo lo caractericé exactamente en la época como un proyecto fascista. Incluso tuvimos mucha discusión entre nosotros, por ejemplo, con Ruy Mauro, pues él no concordaba con el uso de este concepto de fascismo y hablaba de un régimen de seguridad nacional como parte de la ideología que Estados Unidos trajo a América Latina. Sin embargo, yo usé la palabra fascista en un sentido que me parece más complejo, como un régimen de terror del gran capital. Es decir, en el momento que el gran capital siente que necesita de un régimen de terror para poder hacer los cambios que le interesan en la dirección de su forma de base y de la acumulación capitalista. Entonces, creo que nosotros acertamos mucho, a diferencia de otros compañeros que todavía pensaban en una lucha antifeudal. Para nosotros era bastante claro que la conducción del proceso de acumulación capitalista y de modernización, estaba en manos del gran capital internacional y, el grupo en que confiaba para llevar adelante este proceso era básicamente los militares (VIDAL, 2013).

Dos Santos y Mauro Marini entre 1960 y 1964 habían estudiado sistemáticamente el marxismo como culminación de sus estudios filosóficos. En estos años en Brasilia, realizaron un seminario de lectura de El Capital junto con Luis Fernando Víctor, Teodoro Lamounier, Albertino Rodríguez y Perseu Abramo. Este mismo seminario se reorganizó luego del exilio de estos intelectuales en Chile.

Carlos Martins (1998) recuerda que:

\section{GANPHLAC}

Revista Eletrônica da ANPHLAC, ISSN 1679-1061, №. 18, p. 121-138, jan./jul. 2015.

http://revista.anphlac.org.br/ 
El movimiento de lectura de El Capital se transformó en una fiebre mundial. En Sao Paulo, el seminario sobre El Capital reunió por varios años lo mejor de las ciencias sociales y la filosofía de la USP. En Brasilia formamos un grupo que reunía lo mejor del país en torno a este seminario. En Chile organizamos con Fernando Henrique Cardoso, Francisco Weffort, Aníbal Quijano, Pedro Paz y muchos más, un excelente seminario que luego se extendió a otros temas.

De la misma forma, se realizaron otros seminarios de lectura de El Capital en Cuba (organizado por Ernesto Che Guevara) y en Francia, impulsado por Louis Althusser (resultó el libro Leer El Capital). A finales de la década de los sesenta se produjo el regreso a América Latina de representantes de todas estas experiencias. Entre ellos, volvieron a Chile, Marta Harnecker, discípula de Althusser, y Ruy Mauro Marini, quien regresó desde México, donde desarrolló su propio grupo de lectura.

Como señaló el propio Theotonio Dos Santos:

[...] Todas estas experiencias paralelas confluían en un gran movimiento de lectura y discusión del pensamiento marxista como nunca había ocurrido en ninguna otra parte del mundo y llegaba a la vida universitaria de manera insólita. Hasta en las escuelas de psicología y en la de ciencias exactas se formaban grupos de lectura de El Capital y de autores marxistas clásicos y contemporáneos (Apud MARTINS, 1998).

Cabe recordar que Theotonio Dos Santos tuvo una activa militancia política y participación en movimientos sociales, que se extiende a la clandestinidad después del golpe en Brasil de 1964, hasta 1966, cuando se exilia en Chile. Agrega Martins (1998) que:

[...] El eje de su militancia política era su participación en la POLOP de la que fue fundador en 1961 y cuya dirección nacional asume en 1964. La POLOP promovió una dura crítica a los partidos comunistas y al estalinismo y convocaba a una unión de la izquierda revolucionaria contra la política de frente único con la burguesía, propuesta por el PCB, que enmarcaba el movimiento de masas dentro del nacionalismo burgués.

El trabajo de investigación desarrollado por Theotonio Dos Santos 1o convirtió en uno de los más importantes teóricos de la dependencia. Jaime Osorio (2004, p. 136), señala que las críticas de Dos Santos a la teoría del desarrollo y sus formulaciones sobre las diversas "formas de dependencia":

\section{CANPHLAC}

Revista Eletrônica da ANPHLAC, ISSN 1679-1061, No. 18, p. 121-138, jan./jul. 2015.

http://revista.anphlac.org.br/ 
[...] Permitieron mostrar que el estudio de esa problemática era un camino indispensable de análisis. Su libro Imperialismo y dependencia, editado muy posteriormente, recoge buena parte de los mejores trabajos desarrollados en esta época, junto a estudios más recientes sobre el imperialismo y la crisis mundial capitalista, temas hacia los que desplazó su atención.

Por su parte, Vania Bambirra, esposa de Dos Santos, también se integró al Centro de Estudios Socioeconómicos (CESO), de la Universidad de Chile, como integrante del equipo de investigación sobre las relaciones de dependencia de América Latina. Este equipo se había constituido en 1968 bajo la dirección de Theotonio Dos Santos.

Vania Bambirra también se convirtió en una de las precursoras de la teoría marxista de la dependencia. Osorio (2004, p. 136) señala que Bambirra, al criticar la tipología propuesta por Cardoso y Faletto entre economías de enclave y economías con control nacional del proceso productivo, desde aspectos metodológicos hasta aspectos de contenido, en su libro El capitalismo dependiente latinoamericano, propone una nueva clasificación de los países latinoamericanos en función del tipo de estructura productiva que presentan en el momento de la integración monopólica que se produce con posterioridad a la Segunda Guerra Mundial. En este libro establece dos tipos: 1. Estructuras diversificadas, en las cuales aún predomina el sector primario exportador, existiendo, sin embargo, un proceso de industrialización en expansión, y 2. estructuras primario-exportadoras, cuyo sector secundario estaba compuesto casi exclusivamente por industrias artesanales.

Para Bambirra (1999, p. 6), claramente el objetivo que tenía el CESO y sus estudios eran avanzar en superar el pensamiento desarrollista, emprendiendo la tarea de sentar las bases para el desarrollo de la teoría marxista de la dependencia. Agrega que:

[...] El trabajo que intentábamos llevar a cabo en el CESO fue gratamente interrumpido por la victoria de la Unidad Popular que necesitó la colaboración de parte de los miembros del equipo de estudios sobre la dependencia para enfrentar prácticamente las tareas de su ruptura".

\section{GANPHLAC}

Revista Eletrônica da ANPHLAC, ISSN 1679-1061, N. 18, p. 121-138, jan./jul. 2015.

http://revista.anphlac.org.br/ 
Otro intelectual brasileño que dejó huella no solo en Chile, sino también en México fue Ruy Mauro Marini, quien es considerado por muchos cientistas sociales uno de los más brillantes intelectuales militantes de América Latina. Se destacó por su importante obra que subvirtió el pensamiento colonizado dominante y por su militancia coherente.

De cierta manera, la vida de Marini, rodeada de exilios recurrentes, es el vivo resumen de uno de los períodos más intensos de la historia política latinoamericana. Estuvo exiliado en México, en 1965; en Chile, en 1969; y nuevamente en México, en 1974. Su regreso definitivo a Brasil se había producido recién en 1996.

Según el propio Marini, su venida a Chile se gestó por la presión ejercida por sus amigos Theotonio Dos Santos y Vania Bambirra; más la intervención de un político, el entonces senador Salvador Allende y de la Universidad de Concepción y de su Federación de Estudiantes. Marini ${ }^{7}$ señaló, en el año 2007, que:

\section{[...] Efectivamente, aún en México, yo había sido contactado por su presidente, Nelson Gutiérrez, quien me conocía por mis trabajos y por las informaciones de amigos brasileños, entre los cuales Evelyn Singer, profesora en dicha universidad y que había militado conmigo en Brasil. Gutiérrez me había comunicado sobre la existencia de una vacante de profesor titular en el Instituto Central de Sociología y me había consultado sobre mi interés en ocuparla".}

Al igual que sus colegas Do Santos y Bambirra, Marini desarrolla sus estudios en torno a las características del capitalismo dependiente, buscando generar la base para la comprensión no solo de nuestro continente, "sino también de las diversas formas de la superexplotación de la fuerza de trabajo y del subimperialismo" (OSORIO, 2004, p. 138).

En un artículo en la revista chilena Punto Final ${ }^{8}$, el sociólogo y cientista político brasileño, Emir Sader, recuerda su estadía en Chile durante el período de la

\footnotetext{
${ }^{7}$ Ruy Mauro Marini falleció, en la ciudad brasileña de Río de Janeiro, el año de 1997, después de una larga enfermedad.

${ }^{8}$ La revista Punto Final era un medio de comunicación muy cercano del Movimiento de Izquierda Revolucionaria (MIR). Durante la dictadura militar muchos de sus periodistas fueron asesinados o son detenidos desaparecidos.
}

\section{GANPHLAC}

Revista Eletrônica da ANPHLAC, ISSN 1679-1061, №. 18, p. 121-138, jan./jul. 2015.

http://revista.anphlac.org.br/ 
Unidad Popular (1970-1973) y su vinculación con el MIR. Además recuerda a Ruy Mauro Marini:

[... La primera vez que pasé por Chile me quedé en el departamento de Ruy Mauro, en Providencia. Éramos amigos y compañeros de militancia en Brasil, en la organización marxista Política Operaria. Ruy Mauro había sido detenido después del golpe de 1964, en el trabajo de organización de un foco guerrillero con el cual pretendíamos desarrollar un trabajo de propaganda armada de la resistencia a la dictadura (Punto Final, 2014).

Sader señala que su organización heredó el trabajo de Leonel Brizola con sargentos y marinos y a Ruy Mauro le tocó la misión de reorganizarlos. Ese trabajo sufrió una dura represión, Ruy Mauro fue detenido y brutalmente torturado por el servicio secreto de la Marina (CENIMAR). Agrega que:

[...] Cuando fue finalmente liberado, decidimos que él debía salir del país. Ruy Mauro escogió ir a México, pero luego se trasladó a Chile, a Concepción, donde conoció a los dirigentes del MIR. Ahí empezó la intensa colaboración de Ruy Mauro con el MIR, así como la apertura de los espacios por los cuales tantos de nosotros hemos transitado (Punto Final, 2014).

Sader recuerda que en casa de Ruy Mauro conoció a los miembros de la comisión política del MIR, que a menudo hacían reuniones en aquel departamento, a Miguel Enríquez, Bautista Van Schouwen, Luciano Cruz, Edgardo Enríquez, Nelson Gutiérrez y Andrés Pascal Allende. Afirma que era una comisión política, un equipo de dirección, como pocas veces una organización de Izquierda pudo tener. Agrega que:

[...] En ese equipo sobresalía Miguel, un líder revolucionario
extraordinario desde todo punto de vista. Nunca he conocido a alguien
tan capacitado para la dirección política como Miguel. Por representar
la alternativa revolucionaria frente al camino institucional de la
Unidad Popular, el MIR atraía automáticamente a los militantes de
otras organizaciones revolucionarias, en particular de las
latinoamericanas. La concepción internacionalista del MIR -
reivindicada directamente del Che- favorecía aún más la
concentración de militantes de esa corriente en el MIR. Alrededor de
Ruy Mauro Marini se ubicaba el núcleo más cohesionado de
brasileños en el MIR (Punto Final, 2014).

Ruy Mauro Marini, para muchos autores, con su libro Dialéctica de la dependencia, hizo que "el marxismo latinoamericano alcanza su punto más alto en

\section{GANPHLAC}

Revista Eletrônica da ANPHLAC, ISSN 1679-1061, N. 18, p. 121-138, jan./jul. 2015.

http://revista.anphlac.org.br/ 
tanto formulación de las leyes y tendencias que engendran y mueven al capitalismo sui generis llamado dependiente. Esto se alcanzaba luego de una década de arduos estudios y discusiones sobre el tema" (OSORIO, 2004, p. 138). Marini también fue un activo militante del Movimiento de Izquierda Revolucionaria (MIR), realizando numerosos escritos políticos.

\section{La teoría de la dependencia}

Recordemos que la teoría de la dependencia nació directamente relacionada con la crisis del modelo desarrollista de la Comisión Económica para América Latina y el Caribe (CEPAL) impulsado en la década anterior. A través del concepto de dependencia "se quería explicar por qué no se había logrado el desarrollo con aquel modelo -de industrialización por sustitución de importaciones- cuando las condiciones económicas previas habían apuntado a su viabilidad" (REY, 2003, p. $52)$.

Cabe recordar que la CEPAL, fundamentalmente producto de las investigaciones de Raúl Prebisch, afirmaba que para crear condiciones de desarrollo dentro de un país era necesario, entre otros tópicos: controlar la tasa de cambio monetario, poniendo mayor énfasis en políticas fiscales que en políticas monetarias; Promover un papel gubernamental más eficiente en términos de desarrollo nacional; Generar una mayor demanda interna incrementando los sueldos y salarios de los trabajadores; Desarrollar un sistema seguro social más eficiente por parte del gobierno, especialmente para sectores pobres a fin de generar condiciones para que estos sectores puedan llegar a ser más competitivos; y Desarrollar estrategias nacionales que sean coherentes con el modelo substitución de importaciones, protegiendo la producción nacional al imponer cuotas y tarifas a los mercados externos.

Para algunos autores la propuesta de Prebisch y de la CEPAL fue la base de la teoría de la dependencia a principios de los años 50. Sin embargo, para otros autores

\section{GANPHLAC}

Revista Eletrônica da ANPHLAC, ISSN 1679-1061, N. 18, p. 121-138, jan./jul. 2015.

http://revista.anphlac.org.br/ 
como Faletto y Dos Santos luego del fracaso de las propuestas de desarrollo de la CEPAL surge, propiamente, la teoría de la dependencia.

A mediados de la década de los sesentas se publicó este modelo teórico más elaborado. Entre los principales autores de la teoría de la dependencia tenemos a: André Gunder Frank, Raúl Prebisch, Theotonio Dos Santos, Fernando Henrique Cardoso, Edelberto Torres-Rivas, y Samir Amin.

Para muchos autores es el neo-marxismo y no el marxismo ortodoxo clásico el que provee una base para la teoría de la dependencia. Por ejemplo, el enfoque clásico se centra en el análisis del papel de los monopolios extendidos a escala mundial, mientras que el centro del neo-marxismo es proveer una visión desde las condiciones periféricas. Además, el marxismo clásico previó la necesidad de una revolución burguesa en la introducción de procesos de transformación; desde la perspectiva neomarxista y basándose en las condiciones actuales de los países del Tercer Mundo, es imperativo 'saltar' hacia una revolución social, principalmente porque se percibe que la burguesía nacional se identifica fuertemente con posiciones de élite y de la metrópoli más que con posiciones nacionalistas. Por último, afirma Giovanni Reyes (2001):

\begin{abstract}
El enfoque marxista clásico consideraba que el proletariado industrial tenía la fuerza y estaba llamado a ser la vanguardia para la revolución social; el enfoque neo-marxista insistió en que la clase revolucionaria debía de estar conformada por los campesinos para poder llevar a cabo un conflicto revolucionario.
\end{abstract}

Por lo anterior, la teoría de la dependencia se convirtió -afirma Eduardo Rey Tristán (2003, p. 52):

En un apoyo científico al antiimperialismo militante, que reforzaba la orientación latinoamericanista al considerar la situación del continente como un todo (si bien con sus peculiaridades), y que se oponía al postulado comunista respecto a la necesidad de una etapa democrático-burguesa anterior a la revolución socialista.

De acuerdo con la escuela de la dependencia tres son las hipótesis principales relacionadas al desarrollo en los países del Tercer Mundo: Primero, el desarrollo de los países del Tercer Mundo necesita tener un grado de subordinación al centro en contraste con el desarrollo de las naciones centrales cuyo desarrollo fue

\title{
GANPHLAC
}

Revista Eletrônica da ANPHLAC, ISSN 1679-1061, Nº. 18, p. 121-138, jan./jul. 2015.

http://revista.anphlac.org.br/ 
históricamente y es hoy día independiente. Segundo, los partidarios de esta teoría consideran que las naciones periféricas experimentan su mayor desarrollo económico cuando sus enlaces con el centro están más débiles. Eduardo Rey Tristán (2003, p. 52) señala que:

\begin{abstract}
Un ejemplo de esto es el proceso de industrialización que se desarrolló en Latinoamérica durante los años 30s y 40s cuando las naciones del centro estaban concentradas en resolver los problemas de la Gran Depresión y las potencias occidentales estaban involucradas en la Segunda Guerra Mundial”.
\end{abstract}

Una tercera hipótesis indica que cuando los países del centro se recuperan de su crisis y restablecen sus vínculos comerciales y financieros, incorporan de nuevo al sistema a los países periféricos, y el crecimiento y la industrialización de esto país se tiende a ver subordinada. André Gunder Frank señala que:

[...] Cuando los países del centro se recuperan de la guerra u otras crisis que han desviado de su atención de la periferia, la balanza de pagos, inflación y estabilidad política de los países del Tercer Mundo se han visto afectadas negativamente. Por último, el cuarto aspecto se refiere al hecho de que las naciones más subdesarrolladas que todavía operan con sistemas tradicionales feudales son las que tuvieron relaciones más cercanas con el centro" (DOS SANTOS, 2005).

Para Theotonio Dos Santos el paso teórico más importante que ocurrió en las Ciencias Sociales latinoamericanas fue mostrar que la dependencia no era un fenómeno externo que se podía cortar a través del desarrollo económico y de una actitud política más independiente. Dos Santos (1970, p. 7) señala que:

[...] Lo que se explicitó teóricamente fue, sobre todo, el hecho de que la situación de dependencia en que vivimos dentro del sistema capitalista mundial condiciona las estructuras internas de nuestros países, haciéndolos dependientes en su propia constitución.

Pero Theotonio Dos Santos avanza más allá de lo económico tocando tópicos políticos, especialmente en sus escritos realizados durante su estadía en Chile. Para el economista brasileño en el marco de la Guerra Fría se crean las condiciones para el surgimiento de guerras locales que pueden organizar paulatinamente una insurrección popular.

Do Santos (1970, p. 93) afirmó que:

[...] En esas condiciones, las organizaciones políticas de vanguardia no pueden seguir viviendo en las expectativas de una situación

\title{
CANPHLAC
}

Revista Eletrônica da ANPHLAC, ISSN 1679-1061, №. 18, p. 121-138, jan./jul. 2015.

http://revista.anphlac.org.br/ 
insurreccional; pero pueden transformarse en una organización político-militar permanente que organice, a largo plazo, un movimiento insurreccional. El conjunto de esas acciones armadas (que asumen, de acuerdo a características regionales, las más diversas formas) lo que se viene llamando la "guerra popular". El concepto de guerra popular elimina la tesis del "foco", elimina la contradicción foco-partido, la contradicción campo-ciudad, todas ellas alternativas artificiales creadas por la apreciación unilateral de la experiencia de la Revolución Cubana.

La importancia del aporte de los intelectuales brasileños al proceso de la unidad Popular y al MIR queda ratificada en la investigación de Fahra Neghme y Sebastián Leiva. Estos autores sostienen que la dirigencia del MIR, en particular Miguel Enríquez, mantuvo una permanente comunicación con ellos. Por ejemplo, el dirigente que Martín Hernández, dirigente del MIR, plantea que:

\begin{abstract}
[...] Con la mayor parte de los teóricos marxistas de la dependencia, incluso con aquellos que son militantes de la Unidad Popular como Theotonio Dos Santos y Vania Bambirra, Enríquez tiene un constante intercambio intelectual. La base de la convergencia intelectual entre Enríquez, formado en la tradición trotskista, y los teóricos marxistas de la dependencia radica en la ratificación que hace la teoría de la dependencia de la idea central de un programa de transición, a saber la fusión de las tareas de liberación nacional y socialistas (NEGHME y LEIVA, 2000, p. 32).
\end{abstract}

Por último, Andrés Pascal Allende ${ }^{9}$, ex secretario general del MIR desde 1974 hasta 1987, sostiene que la teoría de la dependencia tuvo una gran importancia en la estructuración del discurso y estrategia política del MIR. Pascal Allende que esta teoría, junto con valorizar la existencia de lo que se denominó Tercer Mundo, un mundo de abajo, también se definió a estos países como dependientes del capitalismo central. Y eso los llevó a una lectura desde la propia realidad de América Latina y, en especial, de Chile (SALINAS, 2013, p. 292). Los teóricos de la dependencia que más influyeron en el MIR -afirmó Andrés Pascal Allende- fueron:

[...] André Gunder Frank, muy cercano a ellos; Ruy Mauro Marini, que llega en el gobierno de la Unidad Popular y que llega a ser parte del Comité Central del MIR; Aníbal Quijano, que vivió a fines de los 60' en Chile. "En fin, esa intelectualidad que empieza a alejarse de esa mirada tan euro-céntrica y comienza a mirar nuestras realidades a partir de lo sucedido aquí, una mirada al período de la Colonia, al desarrollo del

\footnotetext{
${ }^{9}$ Entrevista realizada al dirigente del MIR, Andrés Pascal Allende, el 19 de julio de 2011 (SALINAS, 2013, p. 292).
}

\title{
GANPHLAC
}

Revista Eletrônica da ANPHLAC, ISSN 1679-1061, №. 18, p. 121-138, jan./jul. 2015.

http://revista.anphlac.org.br/ 
Capitalismo en Latinoamérica que es distinto al mismo desarrollo en Europa (SALINAS, 2013, p. 292).

\section{Conclusiones}

En Chile, el período político vivido durante la Unidad Popular continúa, pese a los más 40 años transcurridos, siendo controversial. Sin embargo, en los últimos años se ha producido un aumento en las investigaciones y libros sobre los actores que participaron en aquel momento que marcó la historia chilena.

Sin lugar a dudas, como queda establecido en este artículo, un rol protagónico en este proceso político, ya sea participando en centros de estudios, en los partidos políticos de la Unidad Popular o en el Movimiento de Izquierda Revolucionaria (MIR), lo tuvieron intelectuales extranjeros, siendo los más importantes entre ellos los provenientes desde Brasil. Estos intelectuales aportaron al desarrollo de las ciencias sociales en Chile ayudando a su desarrollo de una forma nunca antes vista en el país. Además sus reflexiones en torno a la teoría de la dependencia no sólo contribuyeron al debate académico en Chile sino que se difundieron por América Latina y el mundo.

\section{CANPHLAC}

Revista Eletrônica da ANPHLAC, ISSN 1679-1061, N. 18, p. 121-138, jan./jul. 2015.

http://revista.anphlac.org.br/ 


\section{Bibliografía}

BAMBIRRA, Vania. El capitalismo dependiente latinoamericano. $15^{\mathrm{a}}$ edición, México: Siglo Veintiuno Editores, 1999.

BRUNNER, José Joaquín. Las ciencias sociales en Chile: institucionalización, política y mercado en el caso de la sociología, Documento de Trabajo FLACSO, Santiago, n. 32, diciembre de 1986.

DOS SANTOS, Theotonio. “André Gunder Frank", Revista Contribuciones a la Economía, abril, 2005. Disponível em: <http://www.eumed.net/ce/>. Acesso em: noviembre de 2010.

DOS SANTOS, Theotonio. Dependencia y cambio social, Cuadernos de Estudios Socio-económicos, №11, Santiago: Centro de Estudios Socio Económicos (CESO) Universidad de Chile, 1970.

GARRETÓN, Manuel Antonio. "Las ciencias sociales en Chile. Institucionalización, ruptura y renacimiento": Disponível em: <http://www.manuelantoniogarreton.cl/documentos/07_08_06/sociales.pdf.>. Acesso em: 18 de noviembre de 2010.

MARINI, Ruy Mauro. "Memoria de Ruy Mauro Marino Castellano", Santiago: Centro de Estudios Miguel Enríquez, 2007: Disponível em: $<$ http://www.archivochile.com/Ideas_Autores/maurinirm/01sobre/marini_sobre0000 1.pdf $>$. Acesso em: diciembre de 2010.

MARTINS, Carlos. Theotonio Dos Santos: introducción a la vida y obra de un intelectual planetario. In: Francisco López Segrera (ed.). Los retos de la globalización. Ensayo en homenaje a Theotonio Dos Santos. Caracas: UNESCO, $1998 . \quad$ Disponível em: <http://bibliotecavirtual.clacso.org.ar/ar/libros/unesco/martins.rtf>. Acesso em: $10 \mathrm{de}$ diciembre de 2014.

NEGHME, Fahra y LEIVA, Sebastián. La política del Movimiento de Izquierda Revolucionaria (MIR) durante la unidad popular y su influencia sobre los obreros y pobladores de Santiago. Tesis para obtener el grado de Licenciado en Educación en Historia y Geografía, Santiago: USACH, 2000.

OSORIO, Jaime. Crítica de la economía vulgar Reproducción del capital y dependencia, Colección América Latina y el Nuevo Orden Mundial, México DF: Miguel Ángel Porrua- UAZ, 2004: Disponível em: <http://rimd.reduaz.mx/coleccion_desarrollo_migracion/critica_de_la_economia/Crit ica8.pdf>. Acesso em: diciembre de 2010.

\section{GANPHLAC}

Revista Eletrônica da ANPHLAC, ISSN 1679-1061, №. 18, p. 121-138, jan./jul. 2015.

http://revista.anphlac.org.br/ 
PUNTO FINAL. Latinoamericanos y europeos en el MIR, Santiago, 3 al 16 de octubre, 2014. Disponível em: 〈http://www.puntofinal.cl/814/mir814.php〉. Acesso em: 18 de diciembre de 2014.

REY TRISTÁN, Eduardo. La izquierda revolucionaria uruguaya 1955-1973, Sevilla: Consejo Superior de Investigaciones Científicas-Escuela de Estudios HispanoAmericanos, Universidad de Sevilla-Diputación de Sevilla, n. 17, 2003. Disponível em:

$<$ http://books.google.cl/books?id=5yXNjGlM5VQC\&pg=PA51\&lpg=PA51\&dq=\%2 2nueva+izquierda+revolucionaria\%22\&source $=$ bl\&ots $=x$ 91uwAg5p9\&sig $=J C h O V T$ 1xCPTgzY8TR1fSy4t8O_E\&hl=es\&ei=u5K9TPCTBsmcnAekqOSJDg\&sa=X\&oi=

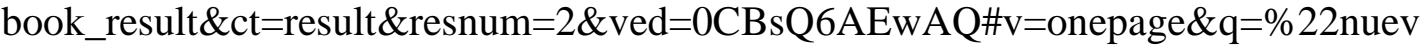
a\%20izquierda\%20revolucionaria\%22\&f=false >. Acesso em: octubre de 2010.

REYES, Giovanni. Principales teorías sobre el desarrollo económico y social, Nómadas Revista Crítica de Ciencias Sociales y Jurídicas, Madrid: Universidad Complutense, 2001. Disponível em: $\langle$ http://pendientedemigracion.ucm.es/info/nomadas/4/gereyes2.pdf $>$. Acesso em: noviembre de 2010.

RODRIGUES DA SILVA, Helenice. Os exílios dos intelectuais brasileiros e chilenos, na França, durante as ditaduras militares: uma história cruzada, Nuevo Mundo Mundos Nuevos Coloquios, Paris: École des Hautes Études en Sciences Sociales, 2007. Disponível em: <http://nuevomundo.revues.org/5791>. Acesso em: 2 de diciembre de 2014.

SALINAS, Sergio. El tres letras. Historia y contexto del MIR. Santiago: RIL Editores, 2013.

VIDAL MOLINA, Paula. Theotonio Dos Santos en el Chile de la Unidad Popular, Cuadernos de Historia, Santiago: Universidad de Chile, n. 39, 2013: Disponível em: $<$ http://www.scielo.cl/scielo.php?pid=S0719-

12432013000200009\&script=sci_arttext>. Acesso em: diciembre de 2014.

\section{GANPHLAC}

Revista Eletrônica da ANPHLAC, ISSN 1679-1061, Nº. 18, p. 121-138, jan./jul. 2015.

http://revista.anphlac.org.br/ 